\title{
Women's Knowledge of Concept of Menopause, Severity, and Climacteric Stage Among Women in Middle Age in Northwest Ethiopia: Community- Based Cross-Sectional Study
}

\author{
Asteray Ayenew ( $\square$ amanuelbiruk0077@gmail.com ) \\ Bahir Dar University \\ Mastewal Yechale \\ Mizan Tepi University \\ Azezu Nigussie \\ Bahir Dar University \\ Nigusu Ayalew \\ Bahir Dar University
}

\section{Research Article}

Keywords: knowledge of menopause, age 40-65, Hot flush, irritability, Northwest Ethiopia

Posted Date: July 1st, 2021

DOl: https://doi.org/10.21203/rs.3.rs-638981/v1

License: (c) (i) This work is licensed under a Creative Commons Attribution 4.0 International License.

Read Full License 


\section{Abstract}

Background: Menopause is the physical, hormonal, psychological, biological events in women menstruation ceases as their age turns to 50's. It is an inevitable part of life in the reproductive life of every women. an appropriate understanding of women about menopause that certain physical, social, mental, and psychological changes occur during menopause and helps them with greater readiness to cope with these changes, to seek medical attention, and other healthy behaviors like exercise, taking vitamins and mineral as supplement. Therefore, the aim of this study was to assess rural women's knowledge of concept of menopause, severity, and climacteric stage among women aged 40-65 years in Northwest, Ethiopia

Methods: Community-based cross-sectional study design was employed from March 6 to 30/ 2020 in Motta district. Simple random sampling was used for the required sample size. The Data was collected by using structured, pre-tested, and interviewer-administered questionnaires and entered in to Epi data version 3.1 then exported to Statistical Package for Social Science version 25 for analysis. Bivariable and multivariable logistic regression was employed and variables with $p$-value $<0.05$ with $95 \%$ confidence interval were identified as significant factors to the outcome variable.

Results: the women's knowledge of concept of menopause only $23.3 \%$. The mean age of study participants were $50.98 \pm 7.89$ years with the majority have no formal education and poor wealth index. The most prevalent types of menopausal symptoms reported were muscular weakness $(79 \%)$ while hot flash $(76.9 \%)$ and decrease sexual desire (52\%) were also prevalent. Moreover, each of the menopausal symptoms were higher among postmenopausal women compared to perimenopause and premonopuse women. Women self-reported differing severity levels of symptoms with high severity reported in $19.1 \%$ of total MRS and $9.1 \%$ had a moderate score of menopausal symptoms. Urban dwellers [AOR $=2.07,95 \% \mathrm{Cl}=$ $(1.12,3.81)]$, college and above educational status $[A O R=4.01,95 \% \mathrm{Cl}=(1.39,11.54)]$, Women with rich wealth index $[A O R=5.98,95 \% \mathrm{Cl}=(3.01,11.87)]$, women had information about menopausal symptoms $[A O R=3.76,95 \% \mathrm{Cl}=(1.86,7.59)]$, history of contraceptive use $[A O R=3.26,95 \% \mathrm{Cl}=(1.94,5.48)]$, and severe score of menopausal symptoms $[\mathrm{AOR}=2.22,95 \% \mathrm{Cl}=(1.17,4.19)]$ were factors significantly associated with knowledge of menopausal symptoms among women aged $40-65$ years.

Conclusion: The knowledge of women regarding menopausal was low. Residency, educational status, wealth index, received information about menopausal symptoms, history of contraceptive use, and menopausal severity score was significantly associated with knowledge of menopause. Thus, to increase knowledge of women on menopause, health education programs need to be integrated in to menopausal health within the health care system. Additionally, it is better to focus on postreproductive health of the women as during reproductive period to ensure the well beings of the women in postreproductive life. Moreover, community based education regardless of the severity of menopause including rural women is recommended. Integrating the menopausal health services with other maternal health services, and empowering women on education is essential for better improving women's health. 


\section{Background}

Menopause is a natural process that every woman experiences as a result of age-related gradual decline of primordial ovarian follicles. It is the permanent cessation of menstruation and is defined as 12-month amenorrhea after the final menstruation[1] with no other pathological cause. Menopause and associated changes like hormonal, biological, physical changes have a negative impact on health and quality of life as well as the wellbeing of middle-aged women[2].

Menopausal symptoms and their severity vary from women to women due to the effects of confounding factors[3] such as body composition, general health condition, lifestyle, social status, and psychological status[4]. Menopausal symptoms, especially the vasomotor and sexual symptoms, are associated with impaired quality of life in women[5]. Moreover, mood changes, bloating, headaches, aches and pains, hot flushes, insomnia, night sweats, tiredness, weight gain, depression, lack of concentration, irritability, forgetfulness, urinary frequency, vaginal dryness, and sexual problems affect women's life extremely[6, 7].

Additionally, hormonal changes at menopause are associated with numerous psychological and physical symptoms such as vasomotor symptoms, urinary tract infection, sleep disturbance, mood alterations, depression, vaginal atrophy, and increased health risks for several chronic disorders including cardiovascular diseases, osteoporosis, and loss of cognitive function [8, 9].

The health care needs of women vary among different stages of reproductive life. Women need to understand the details about the physical changes occurring in their body throughout their life span. They also need to improve knowledge and perception of menopausal symptoms, overall health, and wellbeing [10]. Because of the public health focus on emerging health issues of middle aged women's, perimenopause becomes negligent about their health, and ends up with chronic diseases including stress[11].

A high proportion of women are affected by menopause related symptoms, but the care seeking for all symptoms is not uniform, indicative of a lack of knowledge about the treatable nature of many of these symptoms[11]. As studies have shown that menopause is still treated like a 'taboo' subject in many workplaces[12]. Thus, an appropriate understanding of women's certain physical, mental, social, and psychological changes occurring during menopause helps them with greater readiness to cope with these symptoms[13]. The number of postmenopausal women globally is estimated to increase from approximately 400 million in 1996 to 1.2 billion by 2030 . Thus, an increasing number of women are spending one-third or more of their lives in post-menopause. As a result, this group of women merits greater attention to improve the understanding of their unique set of health-related concerns[1].

In sub-Saharan African women will spend a larger proportion of their lives in postmenopausal age category[14]. In Ethiopia, the 2017 National Census enumerated around 16 million women are in the age group of $25-54$, and around 1.77 million women are in the age groups of above 65 years[15]. Additionally, the prevalence of menopause is $16.8 \%$ among women aged $30-49$ years[16]. 
Women's knowledge of menopausal symptoms is affected by different factors like age, number of births, social, economic, cultural, educational status, and source of information on the menopausal symptoms[17]. Lack of knowledge of menopause causes a wrong or negative perception toward it, leads a stressful postmenopausal period, and leads to clinicalconsequence which requires medical treatment[18]. This make women more frightened to deal with menopause, which directly influences the way they cope with the symptoms [19].

Overall, appropriate understanding of women as certain physical, mental, social, and psychological changes occur during menopause helps them to make them familiar with the changes and how to manage the symptoms as well as to consider available preventive measures [20]. In Ethiopia, unlike menstruation or conception, menopause has not been a major topic of discussion among the public, very little information has been circulated to increase their knowledge on the subject [21]. Menopause receives very little attention especially in Africa because most women feel it is a phase that every woman must go through. Because of the steady increase in life expectancy, many women now live well into their 80s and beyond[22]. Women can now expect to live over a third of their life after the menopause and consequently over the last 40 years or so, there has been an increasing interest in the effect of the menopause on longlife health[23].

A lack of knowledge of menopause causes a wrong or negative perception towards it[24]. This, in turn, leads to a negative attitude towards menopause. On the other hand, if the knowledge about menopause is adequate among women, there would be the correct or right perception which can lead to a positive attitude towards it. Therefore, this study aimed to assess Women's knowledge of concept of menopause, severity, and climacteric stage among women in middle age in Northwest Ethiopia.

\section{Methods}

\section{Study Design, Study Setting, and Period}

Community based cross-sectional study design was conducted from March 3/2020 to March 30/ 2020. The study was conducted in Motta district, Northwest Ethiopia called Hulet Ejju Enesse Woreda, $371 \mathrm{~km}$ away from Addis Ababa, capital city of Ethiopia. The woreda has total of 36 Kebeles. Among those, six were from Motta town, and the rest 30 were from a rural part. The district has one governmental hospital, 9 health centers, twelve nongovernmental clinics, five pharmacies, and 11 drug stores. According to the 2005 census and projected to the current population and from the Motta health bureau. The current estimated total population of the district was about 190,260. Of those, 94,436, and 95, 278 were males and females respectively. From the total number of females 36,898 were in reproductive age group, and 15,512 women were found in the age group of 30-49 [25].

\section{Source Population}

All women in Motta district. 


\section{Study population}

All women aged $40-65$ years old in Motta district in selected kebeles during the data collection period

\section{Inclusion and Exclusion criteria}

\section{Inclusion criteria}

All Women aged 40-65 years old.

\section{Exclusion criteria}

- Women who have stayed less than six months

- Critically ill and unable to communicate at the time of data collection

\section{Sample size determination and sampling procedure}

\section{Sample size determination}

The sample size was determined for the two objectives and the largest sample size was taken. A single population proportion formula was used with the following assumption, 95\% confidence level, and margin of error (0.05) to calculate sample size for the first objective.

$$
\mathrm{n}=\mathrm{z}\left(\frac{\alpha}{2}\right)^{2} \frac{\mathrm{pq}}{\mathrm{d}^{2}}
$$

Where $n=$ required sample size

$Z=1.96(z$ value at $a=0.05)$.

$\mathrm{P}=$ proportion of knowledgeable women (22\%) at Addis Ababa[26].

$d=0.05(5 \%$ margin of error) and $10 \%$ non-response rate.

$$
\mathrm{n}=(1.96) 2 \times(0.22 \times 0.78)
$$

\section{$(0.05) 2$}


$n=290$ with $10 \%$ of non-response rate which gives 435 .

Sample size determination for the second objective was calculated by using the double population formula with Epi-info version 7.2 by considering the following assumptions: $95 \% \mathrm{Cl}$, power $80 \%$,a nonresponse rate of $10 \%$, and the factors are taken from a study conducted in Addis Ababa [26]. By taking the largest sample size 488 was the final calculated sample size.

\section{Sampling techniques and procedures}

There are 36 kebeles in the woreda, and 12 kebeles were selected by the lottery method. Then, the calculated sample size was proportionally allocated for each kebeles based on the number of households. Since the number of house hold in each kebele is not equal, the calculated sample size allocated for each health kebele was proportionally allocated to determine the number of households included in the study from each kebeles. Finally, all randomly selected households were included in the study.

\section{Data Collection tool}

An interviewer administered questionnaire was used to collect the data. First, the tool was prepared in English, and then it were translated to the local language (Amharic), and then retranslated to English. Twelve health extension workers and four BSC midwives were recruited for data collection and supervisor, respectively. Two days training was given to all data collectors for proper filling of the questionnaire.

The questionnaires were including information on socio-demographic characteristics, knowledge assessing questions, reproductive health related factors, and other factors. The Knowledge level was assessed by using the 15 items provided to assess the knowledge level of the women in which each correct response was given a score of 1 and a wrong response score of 0 . Severity of menopausal symptoms was assessed by Menopause Rating Scale (MRS) [27].

\section{Data quality control}

Translation, retranslation, and pretesting of the instrument and pretest were done before the actual data collection with $5 \%$ of the sample population in non-selected Kebeles for accuracy of responses and to estimate the time needed and the whole process of data collection under close supervision. Data were collected by trained data collectors and the collected data was checked and reviewed daily by the supervisors and principal investigator for its completeness Feedback on previous day activities was given, and necessary correction was done on daily bases.

\section{Statistical Analysis}


The collected data was entered and cleaned by using epi data version 3.1, then exported to SPSS version 25 for analysis. Descriptive analysis was conducted to summarize the data and the final result of the study was interpreted in the form of text, figures, and tables. Binary logistic regression analysis was executed to see the association between independent and dependent variables. All explanatory variables with $p \leq 0.2$ in bivariable logistic regression were entered into multivariable logistic regression analysis and a significant association was identified based on $\mathrm{p}<0.05$ and odds ratio with $95 \% \mathrm{Cl}$ in multivariable logistic regression. The final model fitness was checked using the Hosmer-Lemeshow Goodness of Fit test (0.11).

The principal component analysis was computed by the wealth status of the respondents. First, urban and rural wealth was separated and then all variables were subjected to the principal component analysis. In the first analysis, both urban and rural wealth components with Eigenvalues (variance) greater than one were extracted. According to "Kaiser's rule" only those components with Eigenvalues greater than one should be retained [29]. Based on Kaiser's rule, the study decided to retain the first component because it had greater Eigen values (variance) than the other components. In the first component, the variables that had a correlation coefficients score of less than 0.3 were excluded in the second analysis. The correlation coefficient $(r)$ must be 0.30 or greater since anything lower would suggest a really weak relationship between the variables[28]. The variables that had a weak relationship were excluded in the second -factor analysis. The second-factor analysis was performed with the remaining variables. Two components with Eigen values greater than one were extracted. Based on the same rule "Kaiser's rule" the first component was retained because it had greater Eigen values than the second component and this first component was the one used to obtain the wealth index score. Then the reduced urban and rural wealth is coded to poor, medium, and rich and then merged by residence.

\section{Operational definition}

Premenopause: women experienced a regular menstrual cycle for the last three months with no or minimal complaint of related symptoms[29].

Peri-menopause: Refers women found around menopause, marked with the occurrence of the irregular menstrual period or amenorrhea for at least four months, but for less than 12 months and complain some symptoms related to menopause[29].

Post-menopause: Refers to women experiencing amenorrhea for at least12 months with menopausal symptoms which is not attributed due to other reasons[29].

Knowledgeable: For women with a score of a mean and above of knowledge assessing questions were considered as knowledgeable, whereas women who scored less than a mean of knowledge questions were considered as poor knowledge[30].

The severity of menopausal symptoms: Non/minimal (with a score of 0-4), mild (with a score of 5-8), moderate (with a score of 9-15), and sever (with a score of 16-44)[27]. 


\section{Ethical considerations}

Ethical clearance was obtained from the Institutional Review Board (IRB) office of Bahir Dar University College of Medicine and Health sciences. A formal letter was taken to Motta health bureau, Motta town, and to each kebeles administration. Before the actual data collection, each participant was fully informed about the research objectives and a form for written informed consent that was placed at the front page of each questionnaire. Thus, written informed consent was obtained with the sign of the study participant and the actual data collection time. Finally the data collectors attached the consent form with each respondent's questioner. Confidentiality was maintained throughout the study period, and the collected data was anonymous.

\section{Results}

\section{Socio demographic characteristics of respondents}

In this study, a total of 481 respondents have participated with a response rate of $98.5 \%$. The mean age of the respondents was 50.98 with a standard deviation (SD) of \pm 7.89 . About $331(64.7 \%)$ of the respondents had no formal education. Three hundred eighty-three $(79.6 \%)$ of the respondents were rural dwellers. One hundred thirty-five $(28.1 \%)$ of the respondents were in poor wealth status (Table 1 ). 
Table 1

Socio-demographics characteristics of the respondents in Motta district, North West, Ethiopia, 2020 $(n=481)$.

\begin{tabular}{|c|c|c|}
\hline Variables & Frequency & Percentage \\
\hline Age in years & 161 & 33.5 \\
\hline $40-45$ & 103 & 21.4 \\
\hline $46-50$ & 65 & 13.5 \\
\hline $51-55$ & 85 & 17.7 \\
\hline $56-60$ & 67 & 13.9 \\
\hline \multicolumn{3}{|l|}{$61-65$} \\
\hline Religion & 438 & 91.1 \\
\hline Orthodox & 38 & 7.9 \\
\hline Muslim & 5 & 1 \\
\hline \multicolumn{3}{|l|}{ Others* } \\
\hline Educational status & 311 & 64.7 \\
\hline No formal education & 109 & 22.7 \\
\hline Primary & 39 & 8 \\
\hline Secondary & 22 & 4.6 \\
\hline \multicolumn{3}{|l|}{ Collage/university } \\
\hline Marital status & 250 & 52 \\
\hline Married & 231 & 48 \\
\hline \multicolumn{3}{|l|}{ Unmarried** } \\
\hline Residence & 98 & 20.4 \\
\hline Urban & 383 & 79.6 \\
\hline \multicolumn{3}{|l|}{ Rural } \\
\hline Occupation & 207 & 43 \\
\hline Housewife & 158 & 32.8 \\
\hline Farmer & 86 & 17.9 \\
\hline Merchant & 30 & 6.3 \\
\hline Others *** & & \\
\hline
\end{tabular}

*=protestant, catholic, ${ }^{* *}=$ widowed, divorced, ${ }^{* \star *}=$ civil servant, NGO worker, 


\begin{tabular}{|lll|}
\hline Variables & Frequency & Percentage \\
\hline Wealth index & 135 & 28.1 \\
Poor & 203 & 42.2 \\
Medium & 143 & 29.7 \\
Rich & & \\
\hline *=protestant, catholic, $* *=$ widowed, divorced,,$* \star *=$ civil servant, NGO worker, \\
\hline
\end{tabular}

\section{Reproductive characteristics of study participants}

The mean age of menopause was found to be $(44 \pm 4.43)$ years, and the range of onset was 32 and 55 years. Regarding their parity, $278(57.8 \%)$ of them had a parity five and above. Concerning to the history of miscarriage, $52(11 \%)$ of women were a history of less than four miscarriages/abortions in their lifetime. Two hundred twenty (45.7\%) were using contraceptive, of those $105(47.7 \%)$ were used injectables (Table 2). 


\section{Table 2}

Reproductive characteristics of study participants, Motta district, Northwest, Ethiopia, 2020 $(n=481)$.

\section{Variables}

Age of menarche

Under 13

At the age of 13

Older than 13

Did not remember

Parity

$1-4$

$\geq 5$

Abortion/miscarriage

0

$1-3$

$\geq 4$

History of contraceptive use

Yes

No

Type of contraceptives used $(n=220)$

Injectable

Implant

Oral pills

Standard days method

Intra-uterine device

Female Sterilization

History of Hysterectomy /Oophorectomy

Yes
220

261

274

57.8

15

466

\section{Percentage}

17.5

35.1

22.5

24.9

42.8

57.8

154

32

53

11

45.7

54.3

105

47.7

67

30.5

28

12.7

1

0.5

15

6.8

4

1.8

3.1

96.9

No 


\section{Table 2}

Reproductive characteristics of study participants, Motta district, Northwest, Ethiopia, 2020 $(n=481)$.

\begin{tabular}{|lll|}
\hline Variables & Frequency & Percentage \\
\hline Time of last menstrual period & 15 & 3.1 \\
Days ago & 14 & 2.9 \\
Week ago & 110 & 22.9 \\
Months ago & 48 & 10 \\
Before the last 12 months & 260 & 54.1 \\
12 month ago & 19 & 4.0 \\
Before last birth & 15 & 3 \\
had hysterectomy/Oophorectomy & & \\
Age of menopause $(\mathrm{N}=294)$ & 14 & 4.8 \\
$30-35$ & 45 & 15.3 \\
$36-40$ & 113 & 38.4 \\
$41-45$ & 122 & 41.5 \\
$\geq 46$ & & \\
\hline
\end{tabular}

\section{Menopausal symptoms}

Nearly three-fourth (79\%) of study participants has joint and muscular discomfort, $370(76.9 \%)$ reported hot flashes, and $52 \%$ has decreased sexual desire (Table 3 ). 
Table 3

Distribution of menopausal symptoms of respondents, Motta district, Northwest, Ethiopia, 2020

\begin{tabular}{|c|c|c|c|}
\hline Variable & & Frequency $(n=481)$ & Percentage \\
\hline \multirow[t]{2}{*}{ Joint and muscular discomfort } & Yes & 380 & 79 \\
\hline & No & 101 & 21 \\
\hline \multirow[t]{2}{*}{ Hot flushes } & Yes & 370 & 76.9 \\
\hline & No & 111 & 23.1 \\
\hline \multirow[t]{2}{*}{ Heart discomfort } & Yes & 335 & 69.6 \\
\hline & No & 146 & 30.4 \\
\hline \multirow[t]{2}{*}{ Sleep problems } & Yes & 256 & 53.2 \\
\hline & No & 225 & 46.8 \\
\hline \multirow[t]{2}{*}{ Depressive mood } & Yes & 227 & 47.2 \\
\hline & No & 254 & 52.8 \\
\hline \multirow[t]{2}{*}{ Irritability } & Yes & 218 & 45.3 \\
\hline & No & 263 & 54.7 \\
\hline \multirow[t]{2}{*}{ Anxiety } & Yes & 207 & 43 \\
\hline & No & 274 & 57 \\
\hline \multirow[t]{2}{*}{ Physical and mental exhaustion } & Yes & 225 & 46.8 \\
\hline & No & 256 & 53.2 \\
\hline \multirow[t]{2}{*}{ Sexual problems } & Yes & 250 & 52 \\
\hline & No & 231 & 48 \\
\hline \multirow[t]{2}{*}{ Bladder problems } & Yes & 300 & 62.4 \\
\hline & No & 181 & 37.6 \\
\hline \multirow[t]{2}{*}{ Dryness of vagina } & Yes & 211 & 43.9 \\
\hline & No & 270 & 56.1 \\
\hline
\end{tabular}

\section{Severity of menopausal symptoms}

According to the Menopausal Rating Scale (MRI), this measured the number of symptoms that occurred and rates the severity of symptoms. All indicators were then added together to form the index. The index 
scores ranged between 0 indicating that there were no menopausal symptoms to (16-44) indicating that the symptoms were very high or at maximum severity. Ninety two $(19.1 \%)$ and $44(9.1 \%)$ of the respondents had severed scores, and a moderate score of menopausal symptoms respectively (Fig. 1).

\section{Knowledge of menopause}

The overall knowledge of menopause was only $23.3 \%$ with $[95 \% \mathrm{Cl}(19.55,27.1 \%)]$. One hundred thirtyfour $(27.9 \%)$ of the respondents answered hereditary background affecting the occurrence of menopause and $129(26.8 \%)$ were known about menstrual disorder experience before the occurrence of menopause. Three hundred fifty-three (73.4\%) of the respondents reported that they had heard of menopause before this investigation was brought to them (Table 4). The main sources of information about menopause were friends (44.1\%) and relatives (36.4\%). 
Table 4

Knowledge level of respondents, Motta district, Northwest Ethiopia, 2020.

\begin{tabular}{|c|c|c|c|}
\hline Variables & & $\begin{array}{l}\text { Frequency } \\
(n=481)\end{array}$ & Percentage \\
\hline \multirow[t]{2}{*}{ Menstruation stops suddenly } & Yes & 119 & 24.7 \\
\hline & No & 362 & 75.3 \\
\hline \multirow{2}{*}{$\begin{array}{l}\text { Hereditary background affects the time of } \\
\text { menopause occurrence }\end{array}$} & Yes & 134 & 27.9 \\
\hline & No & 347 & 72.1 \\
\hline \multirow[t]{2}{*}{ Sexualities change in menopause women } & Yes & 118 & 24.5 \\
\hline & No & 363 & 73.5 \\
\hline \multirow{2}{*}{$\begin{array}{l}\text { Most of the women experience menstruation disorder } \\
\text { before } \\
\text { menopause occurrence }\end{array}$} & Yes & 129 & 26.8 \\
\hline & No & 352 & 73.2 \\
\hline \multirow{2}{*}{$\begin{array}{l}\text { Most of the women experience hot flashes in the } \\
\text { menopauseperiod }\end{array}$} & Yes & 94 & 19.5 \\
\hline & No & 387 & 80.5 \\
\hline \multirow[t]{2}{*}{ Menopause in women decreases genital infection } & Yes & 94 & 19.5 \\
\hline & No & 387 & 80.5 \\
\hline \multirow{2}{*}{$\begin{array}{l}\text { Menopause decreases Cardiovascular increase in } \\
\text { women }\end{array}$} & Yes & 83 & 17.3 \\
\hline & No & 398 & 82.7 \\
\hline \multirow{2}{*}{$\begin{array}{l}\text { Menopause causes dryness and skin shrivel in } \\
\text { women }\end{array}$} & Yes & 112 & 23.3 \\
\hline & No & 369 & 76.7 \\
\hline \multirow[t]{2}{*}{ Menopause increases extra hair on women's face } & Yes & 82 & 17 \\
\hline & No & 399 & 83 \\
\hline \multirow{2}{*}{$\begin{array}{l}\text { Menopause causes vaginal dryness and painful } \\
\text { sexual intercourse }\end{array}$} & Yes & 103 & 21.4 \\
\hline & No & 378 & 78.4 \\
\hline \multirow[t]{2}{*}{ Menopause causes urinary frequency and dysuria } & Yes & 106 & 22 \\
\hline & No & 375 & 78 \\
\hline \multirow{2}{*}{$\begin{array}{l}\text { Menopause affects the power of concentration and } \\
\text { memory of women }\end{array}$} & Yes & 101 & 21 \\
\hline & No & 380 & 79 \\
\hline \multirow{2}{*}{$\begin{array}{l}\text { Level of stress and depression feeling increase in } \\
\text { menopausal women }\end{array}$} & Yes & 119 & 24.7 \\
\hline & No & 362 & 75.3 \\
\hline
\end{tabular}




\begin{tabular}{|llll|}
\hline Variables & \multicolumn{2}{l|}{$\begin{array}{l}\text { Frequency } \\
\mathbf{( n = 4 8 1 )}\end{array}$} & Percentage \\
\hline $\begin{array}{l}\text { Menopause occurs in women due to increasing } \\
\text { sexual hormones }\end{array}$ & Yes & 125 & 26 \\
\hline Treatment of menopausal symptoms & No & 356 & 74 \\
\hline Ever heared about menopause & Yes & 66 & 13.7 \\
& No & 415 & 86.3 \\
\hline Source of information about menopausal symptoms & Friends & 212 & 73.4 \\
& Hes & 353 & 26.6 \\
& No & 128 & 10 \\
& professionals & 48 & 8.7 \\
& Books & 42 & 9.8 \\
& \&magazines & 47 & 36.4 \\
& TV \&Radio & 145 & 14.8 \\
& Relatives & 71 & 26.8 \\
\hline
\end{tabular}

\section{Factors associated with knowledge of women about menopausal symptoms}

Among factors such as residence, educational status, wealth index, having information about menopausal symptoms, history of using contraceptives, and menopausal severity score was significantly associated with knowledge on menopause. Women who were urban residence were 2.07 times [AOR = $2.07,95 \% \mathrm{Cl}=(1.12,3.81)]$ more likely to know about menopause as compared to those who had a rural residence. Women who had secondary school and above were 5.44 times $[A O R=5.44,95 \% \mathrm{Cl}=(2.33$, 12.68)] more likely to know about menopause compared to women who had no formal education. Similarly, women who had college/ university educational level were 4.01 times [AOR $=4.01,95 \% \mathrm{Cl}=$ $(1.39,11.54)]$ more likely knowledgeable about menopause as compared to those who had no formal education.

Additionally, Women who had a history of contraceptive use were 3.26 times [AOR $=3.26,95 \% \mathrm{Cl}=(1.94$, 5.48)] more likely aware about menopause compared to their counterparts. Women who had a moderate and severe score of menopausal symptoms were 2.99 times $[A O R=2.99,95 \% \mathrm{Cl}=(1.35,6.65)]$ and 2.22 
times $[\mathrm{AOR}=2.22,95 \% \mathrm{Cl}=(1.17,4.19)]$ more likely to know about menopausal symptoms compared to those who had none/minimal menopausal symptoms respectively (Table 5).

Moreover, women with high wealth index were 5.98 times $[\mathrm{AOR}=5.98,95 \% \mathrm{Cl}=(3.01,11.87)]$ more likely to know about menopause compared to those women who were poor. Women who received information about menopause were 3.76 times $[\mathrm{AOR}=3.76,95 \% \mathrm{Cl}=(1.86,7.59)]$ more likely to know about menopause than those who had not received information. 
Table 5

Bivariable and multivariable logistic regression analysis of knowledge about menopausal symptoms, Motta district, Northwest Ethiopia, 2022.

\begin{tabular}{|c|c|c|c|c|c|}
\hline \multirow[t]{2}{*}{ Variables } & \multicolumn{2}{|l|}{ Knowledge } & \multirow[t]{2}{*}{ COR } & \multirow[t]{2}{*}{ AOR } & \multirow[t]{2}{*}{ P-value } \\
\hline & $\operatorname{Good}(n=)$ & Poor(n=) & & & \\
\hline \multirow{2}{*}{$\begin{array}{l}\text { Residence } \\
\text { Urban Rural }\end{array}$} & $39(8.1 \%)$ & $59(12.3 \%)$ & \multirow{2}{*}{$\begin{array}{l}2.81(1.74- \\
4.53) \\
1\end{array}$} & \multirow{2}{*}{$\begin{array}{l}2.07(1.12- \\
3.81) \\
1\end{array}$} & \multirow[t]{2}{*}{$0.020^{\star}$} \\
\hline & 73(15.2\%) & $\begin{array}{l}310 \\
(64.4 \%)\end{array}$ & & & \\
\hline Educational status & $58(12.1 \%)$ & $253(52.6 \%)$ & 1 & 1 & 0.324 \\
\hline No education & $20(4.2 \%)$ & $89(18.5 \%)$ & $\begin{array}{l}0.98(0.56- \\
1.72)\end{array}$ & $\begin{array}{l}0.72(0.38- \\
1.37)\end{array}$ & $0.000 * *$ \\
\hline Primary & $23(4.8 \%)$ & 16(3.3\%) & \multirow{2}{*}{$\begin{array}{l}6.27(3.12- \\
12.61)\end{array}$} & \multirow{2}{*}{$\begin{array}{l}5.44(2.33- \\
12.68)\end{array}$} & \multirow[t]{3}{*}{$0.010 * \star$} \\
\hline Secondary & \multirow[t]{2}{*}{$11(2.3 \%)$} & \multirow[t]{2}{*}{$11(2.3 \%)$} & & & \\
\hline Collage/ university & & & $\begin{array}{l}4.36(1.80- \\
10.55)\end{array}$ & $\begin{array}{l}4.01(1.39- \\
11.54)\end{array}$ & \\
\hline Wealth Index & $18(3.7 \%)$ & $117(1.5 \%)$ & 1 & 1 & 0.16 \\
\hline Poor & $33(6.9 \%)$ & $170(24.3 \%)$ & $1.26(0.68-$ & $\begin{array}{l}1.64(0.82- \\
329)\end{array}$ & \multirow[t]{3}{*}{$0.000^{n \pi}$} \\
\hline Medium & \multirow[t]{2}{*}{$61(12.7 \%)$} & \multirow[t]{2}{*}{$82(17 \%)$} & \multirow{2}{*}{$\begin{array}{l}4.84(2.66- \\
8.78)\end{array}$} & \multirow{2}{*}{$\begin{array}{l}5.98(3.01- \\
11.87)\end{array}$} & \\
\hline Rich & & & & & \\
\hline Received Information & $96(20 \%)$ & $257(53.4 \%)$ & $2.61(1.474 .64)$ & $\begin{array}{l}3.76(1.86- \\
759)\end{array}$ & \multirow[t]{3}{*}{$0.000^{\star \star}$} \\
\hline Yes & \multirow[t]{2}{*}{$16(3.3 \%)$} & \multirow[t]{2}{*}{$112(23.3 \%)$} & \multirow[t]{2}{*}{1} & \multirow{2}{*}{1} & \\
\hline No & & & & & \\
\hline Contraceptive Users & $70(14.6 \%)$ & $150(31.2 \%)$ & \multirow{3}{*}{$\begin{array}{l}2.43(1.57- \\
3.76) \\
1\end{array}$} & \multirow[t]{3}{*}{$\begin{array}{l}3.26(1.94- \\
5.48)\end{array}$} & \multirow[t]{3}{*}{$0.000 * \star$} \\
\hline Yes & \multirow{2}{*}{$42(8.7)$} & \multirow{2}{*}{$219(45.5 \%)$} & & & \\
\hline No & & & & & \\
\hline $\begin{array}{l}\text { Menopause symptom } \\
\text { severity }\end{array}$ & $37(7.7 \%)$ & 198(41.2\%) & 1 & 1 & 0.556 \\
\hline None & $26(5.4 \%)$ & $84(17.5 \%)$ & $\begin{array}{l}1.66(0.94- \\
2.91)\end{array}$ & $\begin{array}{l}1.22(0.64- \\
2.33)\end{array}$ & $0.007^{\star \star}$ \\
\hline Mild & 15(3.1\%) & $29(6.0 \%)$ & $2.77(1.35-$ & $2.99(1.35-$ & $0.014^{*}$ \\
\hline Moderate & $34(7.1 \%)$ & $58(12.1 \%)$ & & & \\
\hline Sever & & & $\begin{array}{l}3.14(1.81- \\
5.44)\end{array}$ & $\begin{array}{l}2.22(1.17- \\
4.19)\end{array}$ & \\
\hline
\end{tabular}




\begin{tabular}{|c|c|c|c|c|c|}
\hline \multirow[t]{2}{*}{ Variables } & \multicolumn{2}{|l|}{ Knowledge } & \multirow[t]{2}{*}{ COR } & \multirow[t]{2}{*}{ AOR } & \multirow[t]{2}{*}{ P-value } \\
\hline & $\operatorname{Good}(n=)$ & Poor(n=) & & & \\
\hline \multirow{3}{*}{$\begin{array}{l}\text { Parity } \\
1-3 \\
\geq 4\end{array}$} & $41(8.5 \%)$ & $162(33.7 \%)$ & 1 & 1 & \multirow[t]{3}{*}{0.177} \\
\hline & \multirow[t]{2}{*}{$71(14.8 \%)$} & \multirow[t]{2}{*}{$207(43 \%)$} & \multirow[t]{2}{*}{$\begin{array}{l}1.35(0.87- \\
2.09)\end{array}$} & \multirow[t]{2}{*}{$\begin{array}{l}0.65(0.35- \\
1.21)\end{array}$} & \\
\hline & & & & & \\
\hline \multirow{4}{*}{$\begin{array}{l}\text { History of abortion } \\
0 \\
1-3 \\
\geq 4\end{array}$} & \multirow{4}{*}{$\begin{array}{l}62(12.9 \%) \\
38(7.9 \%) \\
12(2.5 \%)\end{array}$} & \multirow{4}{*}{$\begin{array}{l}212(44.1 \%) \\
116(24.1 \%) \\
41(8.5 \%)\end{array}$} & 1 & \multirow{3}{*}{$\begin{array}{l}1 \\
1.50(0.82- \\
2.77)\end{array}$} & 0.19 \\
\hline & & & $\begin{array}{l}1.12(0.70- \\
1.78)\end{array}$ & & \multirow[t]{3}{*}{0.79} \\
\hline & & & \multirow{2}{*}{$\begin{array}{l}1.0(0.49- \\
2.02)\end{array}$} & & \\
\hline & & & & $\begin{array}{l}0.88(0.34- \\
2.25)\end{array}$ & \\
\hline \multirow{4}{*}{$\begin{array}{l}\text { Menopausal stage } \\
\text { Premenopause } \\
\text { Perimenopause } \\
\text { Postmenopause }\end{array}$} & \multirow{4}{*}{$\begin{array}{l}5(1 \%) \\
36(7.5 \%) \\
71(14.8 \%)\end{array}$} & \multirow{4}{*}{$\begin{array}{l}39(8.1 \%) \\
103(21.4 \%) \\
227(47.2 \%)\end{array}$} & 1 & 1 & 0.080 \\
\hline & & & \multirow{3}{*}{$\begin{array}{l}2.76(0.99- \\
7.45) \\
2.44(0.92- \\
6.42)\end{array}$} & \multirow{3}{*}{$\begin{array}{l}2.85(0.88- \\
9.23) \\
2.78(0.90- \\
8.61)\end{array}$} & \multirow[t]{3}{*}{0.075} \\
\hline & & & & & \\
\hline & & & & & \\
\hline \multirow{4}{*}{$\begin{array}{l}\text { Previous history of } \\
\text { Hysterectomy/Opharectomy } \\
\text { Yes } \\
\text { No }\end{array}$} & $6(1.2 \%)$ & $7(1.5 \%)$ & \multirow{4}{*}{$\begin{array}{l}2.93(0.96- \\
8.89) \\
1\end{array}$} & \multirow{2}{*}{$\begin{array}{l}1.79 \\
(0.42- \\
7.67)\end{array}$} & \multirow[t]{4}{*}{0.42} \\
\hline & \multirow[t]{3}{*}{$106(22 \%)$} & \multirow[t]{3}{*}{$362(75.3 \%)$} & & & \\
\hline & & & & \multirow{2}{*}{1} & \\
\hline & & & & & \\
\hline Note: Statically significant at & $C l,{ }^{*} p-v a l$ & $0.05, * * p-$ & $e<0.01, * \star z$ & $e<0.001,1$ & \\
\hline
\end{tabular}

\section{Discussion}

The overall knowledge of menopause was $23.3 \%$ with $[95 \% \mathrm{Cl}(19.55,27.1 \%)]$. This finding was consistent with the study conducted in Adama 20.9\%[31], Addis Ababa 22\%[26], and Namakkal district (20\%) [32]. However, the finding of this study was higher than the study conducted in Egypt Cairo[33]. The possible explanation could be variation in the study population socio-demographic characteristics, study desighn, and greater than half of their study participants had no formal education.

The finding of this study is lower than the study conducted in Egypt[34], and Botswana[35]. The variation might be due to differences in the study population, sampling technique and could be, Egypt is a medium developed country and expected to have good life expectancy as well as more educated and it was an institutional based. Another possible explanation could be since the study conducted in Botswana was in 
a higher age group (50-90), which could be the reason for the difference, which will be exposed to recall biases. Additionally, $57.2 \%$ of Botswana respondents had formal education as well as it was an institution-based cross-sectional study while $35.3 \%$ of respondents in this study had formal education.

The finding of this study was lower than studies conducted in Western Odisha 50\%[36], Iran (38.5\%)[37], India (32.72\%)[38], and United Arab Emirates (33.5\%)[30]. The possible explanation could be due to differences in economic status, source of information, and educational level. For example, a study conducted in Iran, $68.4 \%$ of respondents were from moderate socioe-conomic status, and $69 \%$ of respondents had secondary education, and 95\% of respondents in the United Arab Emirates were received information about menopausal symptom. Additionally, only seven variables were used to assess knowledge in Western Odisha, and it was also done in urban while 15 variables in this study were used.

Hot flash and sexuality change are the most frequently reported menopausal symptoms by $52 \%$ and $58 \%$, respectively in Namibia[39]. However, in this finding, hot flash and sexuality change lower which were $19.5 \%$ and $24.5 \%$, respectively. The possible explanation could be since "Hot flushes" are usually the most frequent postmenopausal symptom, women living in hot climate regions[40]. An additional explanation could be differences in lifestyle, social status, and body composition of individuals[4].

This study revealed that urban residence was significantly associated with knowledge of menopause. This result is supported by a study done in Korea[41]. The possible explanation could be due to the accessibility of information and health seeking behavior of women who had rural residence[42]. The other explanation could be due to women who had urban residence, being more educated, and near to mass media. According to different scholars, women who had urban residences experienced more severe menopausal symptoms, due to differences in lifestyle, including nutrition, become more concerned, and become knowledgeable[43].

This result revealed that knowledge about menopausal symptoms was significantly associated with secondary level and tertiary education. This result is supported by a study conducted in Adama[31], Egypt [44], Korea[13], India[45], and Brazile[46]. The possible explanation could be, as the women's educational status increases, their health seeking behavior could be also increasing and might be eager to know about her health status[47]. Besides, more educated women might have the interest to ask, read, listen and watch any information source related to their wellbeing as well as literate people use more health care services and have more access to databases.

This result showed that those rich women were significantly associated with knowledge of menopausal symptoms. This study is supported by a study conducted in Egypt[44] and Brazil[46]. The reason for this might be due to better access to health care services, individual concern on safety, and better access toinformation related to their needs. Another explanation could be improving the financial position of women improves the quality of life in menopause, which can be due to increased access to health care services and receive counseling to manage menopausal symptoms[48]. 
This result revealed that received information about menopausal symptoms is significantly associated with knowledge on menopausal symptoms. This result is supported by a study conducted in Addis Ababa[26], Bangaluru[49], and Korea[50]. This is due to the linear associations of having information about menopause could help the women to have more realistic expectations about the menopausal period and awareness about menopausal symptoms[51].

This study revealed that the use of contraceptives is significantly associated with knowledge of menopausal symptoms. The reason might be due to frequent contact with health professionals might be gain information relate menopausal symptoms with side effects of contraceptives. This study revealed that a woman who had a moderate and severe score of a menopausal symptom is significantly associated with knowledge on menopausal symptoms. The possible explanation could be due to increasing their health seeking behavior as severity increase [42]and as the severity of menopausal symptom Increase their concern also increase.

\section{Conclusion}

The knowledge of women on menopause was low. Residency, educational status, wealth index, received information about menopausal symptoms, history of contraceptive use, and menopausal severity score was significantly associated with knowledge about menopausal symptoms. Thus, to increase knowledge of women on menopause, health education programs need to be integrated in to menopausal health within the health care system. Additionally, it is better to focus on postreproductive health of the women as during reproductive period to ensure the well beings of the women in postreproductive life. Moreover, community based education regardless of the severity of menopausal including rural women is recommended. Integrating the menopausal health services with other maternal health services, and empowering women on education is essential for better improving maternal health.

\section{Strength and limitations of the study}

Since the study is community-based study and a simple random sampling technique, it is representative of the source population. Cross sectional nature of the study might lack the causal relationship between dependent and independent variables. Additionally, social desirability might be occurring due to the cultural nature of our society, and they could hide their exact age.

\section{Declarations}

\section{Acknowledgment}

We would like to thank all health sciences students of each department of the College of Medicine and Health Science, Bahir Dar University.

\section{Authors Contributions}


All authors (AA, MY, AN, and NA) contributed to the conception of a research idea, study design, data analysis, interpretation, and manuscript write up. All the author(s) read and approved the final manuscript.

\section{Funding}

No funding was obtained for this study

\section{Corresponding author}

Correspondence to Asteray Assmie Ayenew

\section{Ethical declarations}

\section{Ethics approval and consent to participate}

Ethical clearance was obtained from the Institutional Review Board (IRB) office of Bahir Dar University College of Medicine and Health sciences. Written informed consent was taken from each study participant after they understood the purpose of the study. All the subjects' data were kept in full confidentiality and were not being disclosed to an unauthorized person. Additionally, all methods were performed in accordance with the relevant guidelines and regulations.

\section{Availability of data and materials}

The datasets used and/or analyzed during the current study are available from the corresponding author on reasonable request.

\section{Consent for publication}

Not applicable.

\section{Competing interests}

The authors declare that they have no competing interest.

\section{References}

1. Organization, W.H., Research on the menopause in the 1990s: report of a WHO scientific group. 1996. 
2. Makuwa, G.N., S.R. Rikhotso, and F.M. Mulaudzi, The perceptions of African women regarding natural menopause in Mamelodi, Tshwane district. curationis, 2015. 38(2): p. 1-7.

3. llankoon, I.M.P.S., K. Samarasinghe, and C. Elgán, Menopause is a natural stage of aging: a qualitative study. BMC Women's Health, 2021. 21(1): p. 47.

4. Kothiyal, P. and M. Sharma, Post menopausal quality of life and associated factors-A. Journal of Scientific and Innovative Research, 2013. 2(4): p. 814-823.

5. Ibrahim, Z., W. Sayed Ahmed, and S. El-Hamid, Prevalence of menopausal related symptoms and their impact on quality of life among Egyptian women. Clin Exp Obstet Gynecol, 2015. 42(2): p. 1617 .

6. Waidyasekera, H., et al., Menopausal symptoms and quality of life during the menopausal transition in Sri Lankan women. Menopause, 2009. 16(1): p. 164-170.

7. Greendale, G.A. and E.B. Gold, Lifestyle factors: are they related to vasomotor symptoms and do they modify the effectiveness or side effects of hormone therapy? The American Journal of Medicine, 2005. 118(12): p. 148-154.

8. Wambua, L.T., African perceptions and myths about menopause. East Afr Med J, 1997. 74(10): p. 645-6.

9. Borker, S.A., P.P. Venugopalan, and S.N. Bhat, Study of menopausal symptoms, and perceptions about menopause among women at a rural community in Kerala. Journal of mid-life health, 2013. 4(3): p. 182-187.

10. Bothe S, P.R., Assessment of knowledge about Climacteric Symptoms in perimenopausal Journal of Nursing and Health Science, 2015. 4.

11. Sajitha, S., Menopause related symptoms and their correlates: a community based cross sectional study in Kollam district, Kerala. 2017, SCTIMST.

12. Sridharan, P. and S. Thiyagarajan, An Assessment of Women's Awareness and Symptoms in Menopause (A Study with Reference to Academic Women's at Sri Lanka).

13. Kwak, E.K., H.S. Park, and N.M. Kang, Menopause knowledge, attitude, symptom and management among midlife employed women. Journal of menopausal medicine, 2014. 20(3): p. 118-125.

14. Pathak, R. and P. Parashar, Age at menopause and associated bio-social factors of health in Punjabi women. The open anthropology journal, 2010. 3(1).

15. PC, C., The 2017 population and housing census of Ethiopia. 2017.

16. EDHS, E., demographic and health survey 2016: key indicators report. The DHS Program ICF, 2016.

17. Leon P, ChedrauiP, Hidalgo L, Ortiz F. Perceptions and attitudes toward the menopause among middle aged women from Guayaquil, Ecuador. Maturitas. 57(3):233-238.2007.

18. Adewuyi T, A.E., Perception and attitudes of Nigerian women towards menopause. Procedia-Social and Behavioral Sciences, 2010. 5.

19. etal, H.S., Women's knowledge, attitude and practice towards Menopause and hormone replacement therapy. Journal of Ayub Med Coll Abbottabad 2014. 
20. Barathi. K, D.K.S., Symptom prevalence during menopause and factors associated with symptoms and menopausal age. Maturitas, 2011.

21. Metintas S, Arykan I, Kalyoncu C, Ozalp S. Menopause rating scale as a screening tool in rural Turkey. Rural Remote Health 2010;10:1230.

22. Leon, P., et al., Perceptions and attitudes toward the menopause among middle aged women from Guayaquil, Ecuador. Maturitas, 2007. 57(3): p. 233-8.

23. Metintas, S., et al., Menopause Rating Scale as a screening tool in rural Turkey. Rural Remote Health, 2010. 10(1): p. 1230.

24. Hall, L., et al., Meanings of menopause: cultural influences on perception and management of menopause. J Holist Nurs, 2007. 25(2): p. 106-18.

25. Commission, P.C., The 2005 population and housing census of Ethiopia. 2010.

26. Eshetu, N., Knowledge, Attitude and Associated Factors of Women Aged 30-49 Years Towards Menopause In Gulele Sub-City of Addis Ababa, Ethiopia. 2015, Addis Ababa University.

27. Heinemann, L.A., P. Potthoff, and H.P. Schneider, International versions of the menopause rating scale (MRS). Health and quality of life outcomes, 2003. 1(1): p. 28.

28. Osei, M., Principal Component and Factor Analysis of Macroeconomic Indicators. IOSR Journal Of Humanities And Social Science (IOSR-JHSS), 2018.

29. Harlow, S.D., et al., Executive summary of the Stages of Reproductive Aging Workshop + 10: addressing the unfinished agenda of staging reproductive aging. The Journal of Clinical Endocrinology \& Metabolism, 2012. 97(4): p. 1159-1168.

30. Hamid, S., et al., Women's knowledge, attitude and practice towards menopause and hormone replacement therapy: a facility based study in Al-Ain, United Arab Emirates. Journal of Ayub Medical College Abbottabad, 2014. 26(4): p. 448-54.

31. Abdela, M., assessment of knowledge, attitude and associated factors of menopausal women (aged 40 years and above) toward menopause in bole and lugo sub city of Adama town, Oromia regional state, central Ethiopia, april to may 2018. 2018, Addis Ababa Universty.

32. Mrs. Jayadeepa, et al A Descriptive study to assess te knowledge on menopusal symptoms among menopusal women residing in selected villages at NAMAKKAL district, intrnational journal of cuurent research,vol 10, 2018.

33. Abdelwahed Shams-Eldin, A., KNOWLEDGE, ATTITUDE AND SEVERITY OF MENOPAUSAL SYMPTOMS AMONG WOMEN ATTENDING PRIMARY HEALTH CARE CENTERS IN CAIRO, EGYPT. AlAzhar Medical Journal, 2018. 47(2): p. 423-434.

34. Elkazeh, E.A.E.E. and A.M.A. El-Zeftawy, Knowledge of Women in Reproductive Age about Menopausal Problems and Preventive Health Behaviors in Tanta City, Al-Gharbyia Governorate, Egypt. population. 3: p. 11.

35. Ama.O, N.E., Menopausal Perceptions and Experiences of Older Women from Selected Sites in Botswana. Journal of Advances in Sexual Medicine, 2013. 
36. Satpathy, M., A Study on the Knowledge and Awareness about Menopause among Middle Aged Women from Western Odisha. Age, 2016. 40(45): p. 39-39.

37. Noroozi, E., et al., Knowledge and attitude toward menopause phenomenon among women aged 4045 years. Journal of education and health promotion, 2013. 2.

38. Pathak, V., N. Ahirwar, and S. Ghate, Study to assess knowledge, attitude and practice regarding menopause among menopausal women attending outdoor in tertiary care centre. Int J Reprod Contracept Obstet Gynecol, 2017. 6(5): p. 1848-1853.

39. Hoëbes, K.H. and K. Matengu, Knowledge and understanding of menopause and menopausal symptoms: A Namibian perspective. Int J Health Sci, 2014. 2: p. 163-83.

40. Mukarram, M. and H. Student. Hot Flash Frequency and Vasomotor Symptom Bother Considering Extreme Temperatures. in APHA 2017 Annual Meeting \& Expo (Nov. 4-Nov. 8). 2017. American Public Health Association.

41. Ju, H., et al., Comparative study on climacteric symptoms, knowledge of menopause and menopausal management of middle aged women between urban and rural areas. Korean Journal of Women Health Nursing, 2013. 11(1): p. 27-37.

42. Khan, S., et al., Health seeking behaviour among post-menopausal women: a knowledge, attitude and practices study. International Journal of Community Medicine and Public Health, 2016. 3(7): p. 1777.

43. Hakimi, S., et al., Comparing the pattern of menopausal symptoms, concern and attitudes in urban and rural postmenopausal Iranian women. Journal of menopausal medicine, 2018. 24(1): p. 50-55.

44. Orabi, E., Effect of health education intervention on knowledge, and attitude regarding menopausal period among premenopausal female employees. The Egyptian Journal of Community Medicine, 2017. 35(30): p. 71-84.

45. Ms. Veerpal Kaur MVK, Mrs. Anita Prakasam. A Descriptive Study to Assess the Knowledge Regarding Premenopausal Symptoms and Its Management among Middle aged Women in Bhucho Mandi, Bathinda, Punjab.". wwwiosrjournalsorg 2019;8(3).

46. de Arruda Amaral, I.C., et al., Factors associated with knowledge about menopause and hormone therapy in middle-aged Brazilian women: a population-based household survey. Menopause, 2018. 25(7): p. 803-810.

47. Ikeme A, Okeke TC, Akogu S, Chinwuba N. Knowledge and perception of menopause and climacteric symptoms among a population of women in Enugu, South East, Nigeria. Ann Med Health Sci Res 2011;1(1):31 - 6. 16. Jassim GA, Al-Shboul Q. Attitudes of Bahraini women towards

48. Mirhaghjou SN, et al. Quality of life and its determinants in postmenopausal women: apopulationbased study. Appl Nurs Res. 2016;30:252-256. doi:10.

49. CP, S., A STUDY TO EVALUATE THE EFFECTIVENESS OF STRUCTURED TEACHING PROGRAMME REGARDING KNOWLEDGE ON PREVENTIVE MEASURES OF UTERINE PROLAPSE AMONG MULTIPAROUS WOMEN IN CHIGATERI DISTRICT HOSPITAL, AT DAVANGERE. 2012.

50. Kim, I.K., H.M. Choi, and M.H. Kim, Menopausal knowledge and management in peri-menopausal women. The Journal of Korean Society of Menopause, 2012. 18(2): p. 124-131. 
51. Koyuncu, T., A. Unsal, and D. Arslantas, Evaluation of the Effectiveness of Health Education on Menopause Symptoms and Knowledge and Attitude in Terms of Menopause. Journal of epidemiology and global health, 2018. 8(1): p. 8-12.

\section{Figures}

\section{Severity of menopusal symptomes}

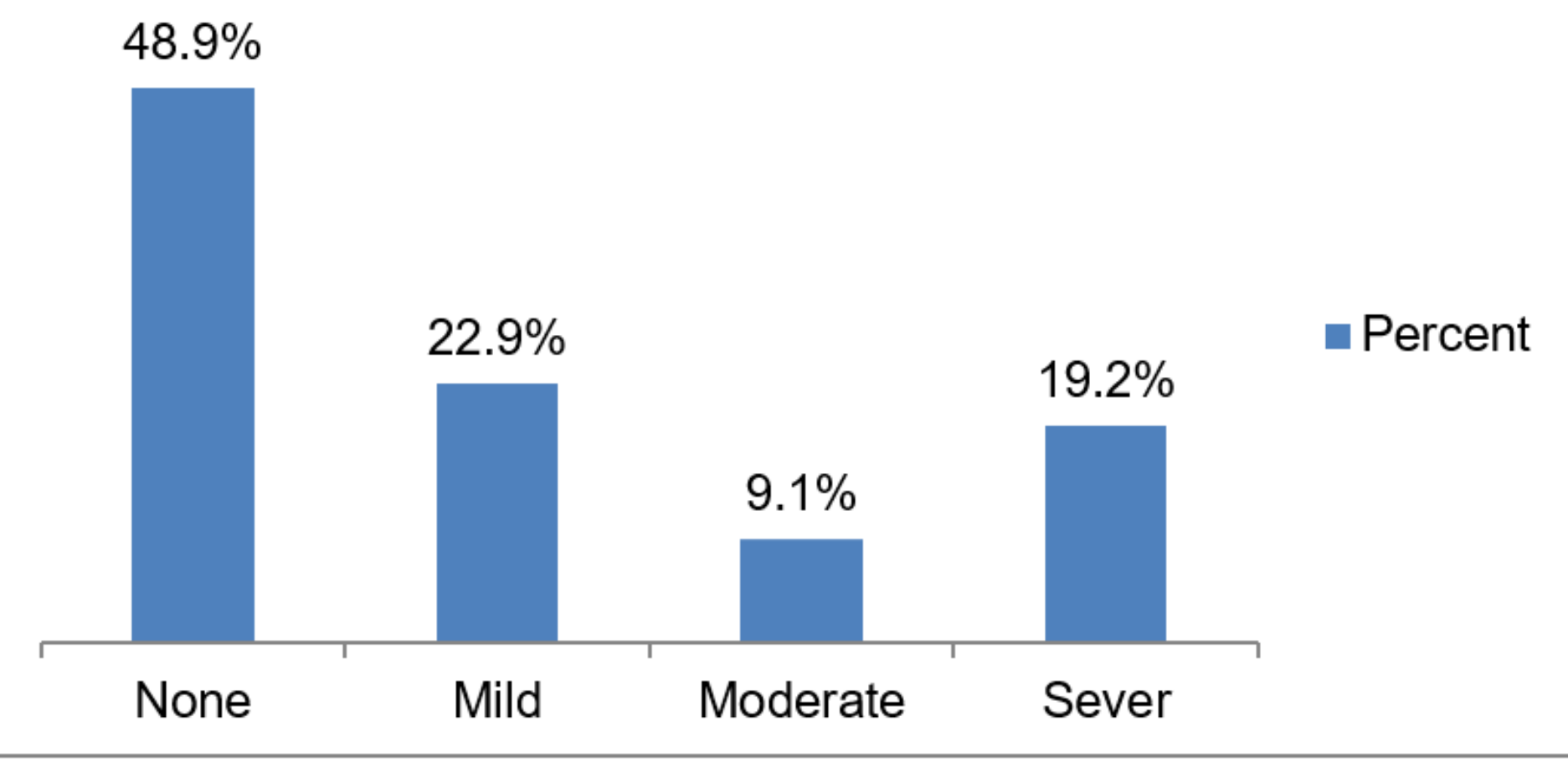

Figure 1

MRI score of menopausal symptoms of respondents, Motta district, Northwest Ethiopia, 2020 